\title{
Dynamic Ride Height Adjusting Controller of ECAS Vehicle with Random Road Disturbances
}

\author{
Xing Xu, Long Chen, Liqin Sun, and Xiaodong Sun \\ School of Automotive and Traffic Engineering, Jiangsu University, Zhenjiang 212013, China \\ Correspondence should be addressed to Xing Xu; xuxing@mail.ujs.edu.cn
}

Received 20 August 2013; Accepted 24 September 2013

Academic Editor: Hui Zhang

Copyright (C) 2013 Xing Xu et al. This is an open access article distributed under the Creative Commons Attribution License, which permits unrestricted use, distribution, and reproduction in any medium, provided the original work is properly cited.

The ride height control system is greatly affected by the random road excitation during the ride height adjusting of the driving condition. The structure of ride height adjusting system is first analyzed, and then the mathematical model of the ride height adjusting system with the random disturbance is established as a stochastic nonlinear system. This system is decoupled using the differential geometry theory and stabilized using the Variable Structure Control (VSC) technique. The designed ride height control system converges in probability to be asymptotically stable in the sliding motion band, and the desired control law is solved to ensure the stable adjustment of the ride height system. Simulation results show that the proposed stochastic VSC method is effective for the dynamic adjusting of the ride height. Finally, the semiphysical rig test illustrates the applicability of the proposed scheme.

\section{Introduction}

Ride height adjustment is one of the advantages for Electronically Controlled Air Suspension (ECAS) [1,2]. The height adjustment, which contains the aerothermodynamics and vehicle dynamic processes of variable mass system, is accomplished by charging/discharging gas into/from air spring. The ECU of the ride height adjusting system can automatically regulate the ride height (maintaining or switching the ride height of the vehicle) to improve the performance of the suspension, according to the different driving states.

In the past several years, the study of ride height adjusting system attracted the attention of researchers all over the world. A prototype self-leveling active suspension system for road vehicles is presented to analyze the characteristic of the system [3]. In fact, the adjustment of the ride height system, which belongs to multidomain dynamics, is a process where the energy of the compressed air is converted to potential energy of vehicle sprung mass. Since the ride height adjusting system includes the continuous dynamic system state and the discrete logic state of the height mode switch, a novel approach for the verification of hybrid systems based on linear and mixed-integer linear programming for the electronic height control was proposed $[4,5]$. Then, the ride height control system based on the model was designed.
A multibody dynamic model of an air suspension vehicle by using Lagrange's method was built, and a ride height simulation under the condition of a step input using PID and PD control strategy was performed [6]. Some advanced control algorithms were also used to improve the adjusting performance of the ride height system. Chen et al. used the combined PID and VSC method to control the HydroPneumatic Suspension, which could eliminate the oscillation and improve the control accuracy of the ride height system [7]. Yu et al. studied the fuzzy control of the ride height system, and the proposed control system has good robustness for the case of the changed structure parameters [8]. Yang et al. further studied the charging/discharging gas system of ECAS, designed the inductance integral height measuring system for real-time tracking information of ride height, and tried to improve the stability of the ride height adjustment system by adopting gearshift integral PID/PWM algorithm [9-11]. Feng and Du adopted the Fuzzy/PWM algorithm on the electronic controlled air suspension of semitrailer based on a quarter-car model, and then the phenomenon of overshoot and oscillation can be overcome effectively [12]. Kim and Lee used a sliding mode control algorithm to improve the tracking accuracy of the control and to overcome nonlinearities and uncertainties in the air suspension system [13]. However, the dynamic adjusting, especially the stability 


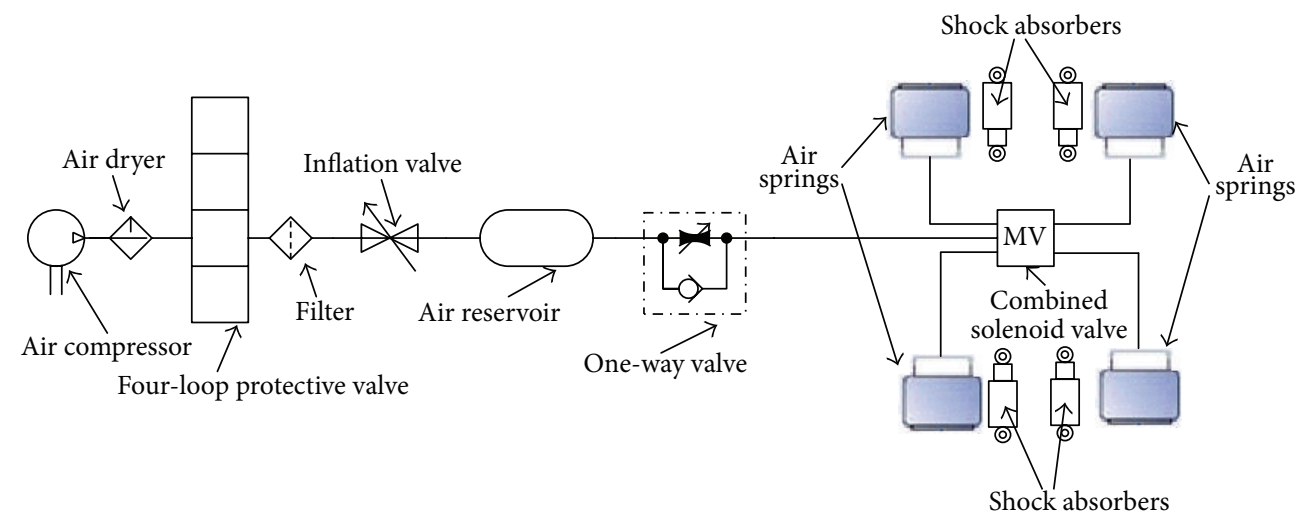

FIGURE 1: Pneumatic scheme of the ride height system for full vehicle.

control with respect to the random disturbances, has little research, but we can find some theories to apply the nonlinear system with disturbances $[14,15]$. According to the characteristics of the nonlinear stochastic adjustment system, the ride height control system is designed by using the stochastic VSC technique in the present paper. The stochastic VSC law is solved by the stabilization in a certain probability, and this may achieve the stable adjustment of the dynamic ride height.

This paper is organized as follows. In Section 2, the ride height adjusting system is described. In Section 3, the dynamic model with random disturbances is built. In Section 4, we design a stochastic variable structure controller to achieve the stable adjusting of ride height, and the simulating results of comparing the algorithm proposed in this paper with PID algorithm are carried out. Experimental results show the effectiveness of the proposed method, as shown in Section 5. Conclusions are provided in Section 6.

\section{Structure of Ride Height Adjusting System}

The structure of ECAS system is shown in Figure 1. The high pressure air in air springs is exchanged with air reservoir or the atmosphere, which can lead to the state changing of ride height adjusting system. Thus, the considered system is characterized by pneumatic and mechanical coupling.

To further demonstrate the working principle of ride height adjusting system, a quarter ride height system model is used to describe the changing process of the ride height, as shown in Figure 2. Supposing that the sprung mass of suspension is a centralized mass $M$, the displacement of the sprung mass is changed by charging/discharging compressed air, and the ride height is adjusted to satisfy the vehicle driving performance. In the charging process, air from the air reservoir is supplied into the air spring through the pipeline as shown in Figure 2(a). In the discharging process, air from the air spring is released into the atmosphere through the pipeline as shown in Figure 2(b). In the practical application, the volume change rate and effective area of a diaphragm air spring are constant, and the height of the diaphragm air spring is similar to a piston motion of engine. Therefore, we can see that the characteristics of air springs and compressed gas lead to the nonlinearity of the ride height adjustment system. Additionally, the ride height adjustment system is disturbed by the road excitation when the vehicle was driven at different road conditions and speeds.

\section{Mathematical Model of Ride Height Adjusting System with}

The random disturbance caused by irregularities of the road surface is filtered by the tire system, and it can be unified into the random change of suspension deflection [16]. The ride height adjusting system includes the processes of variable mass thermodynamics and vehicle dynamics, and a quartervehicle mathematical model is shown as [17]

$$
\begin{gathered}
m_{s} \ddot{Z}_{s}=\left(P_{3}-P_{a}\right) A_{e}-m_{s} g \\
-\left(C_{3}^{(1)} \dot{Z}_{s}+C_{3}^{(2)} \dot{Z}_{s}^{2}+C_{3}^{(3)} \dot{Z}_{s}^{3}\right)-k_{s} \omega \\
V_{3} \dot{P}_{3}=-\kappa P_{3} \Delta V \dot{Z}_{s}+\kappa R T_{3} q_{m} \\
V_{3}=V_{30}+\Delta V Z_{s}
\end{gathered}
$$

where $m_{s}$ is the sprung mass; $Z_{s}$ is the absolute displacement of sprung mass; $P_{3}$ is the internal absolute pressure of air spring; $P_{a}$ is the atmospheric pressure; $A_{e}$ is the effective area of air spring; $g$ is the acceleration of gravity; $C_{3}^{(i)}, i=1,2,3$ are one-degree term, quadratic term, and three-degree term of damping, respectively; $k_{s}$ is the interference coefficient, relating to the character parameters of tire, air spring, and shock absorber; $\omega$ is the Gauss white noise with mean value of zero, relating to the irregularity of road surface and vehicle speed; $\kappa$ is the adiabatic coefficient; $q_{m}$ is the mass flow rate of inflow gas (or the outflow gas, which is negative); $T_{3}$ is the internal temperature of air spring; $V_{3}$ is the volume of air spring (subscript 0 stands for the initial volume of air spring), and $\Delta V$ is the volume change rate of air spring.

Choose the state variable of ride height tracking system as $X=\left[\begin{array}{lll}X_{1} & X_{2} & X_{3}\end{array}\right]^{T}=\left[\begin{array}{lll}Z_{s} & \dot{Z}_{s} & P_{3}\end{array}\right]^{T}$; that is, $X_{1}, X_{2}$, and $X_{3}$, 


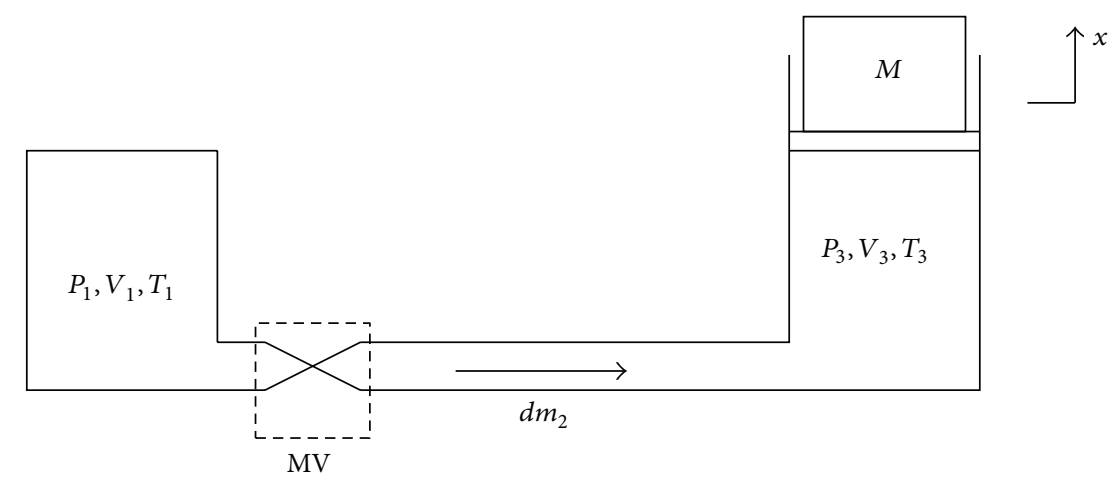

(a) Charging compressed air into air spring

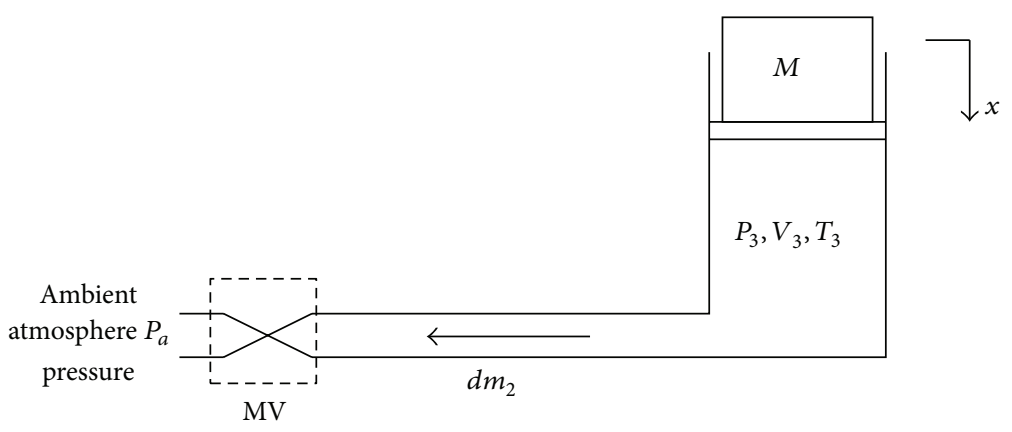

(b) Discharging compressed air from air spring

FIGURE 2: Structure of ride height adjustment for a quarter vehicle.

separately, are the ride height, the rate of ride height changing, and the pressure of air spring, so we can rewrite (1) as

$$
\begin{gathered}
\dot{X}=f(X)+g(X) u+q(X) \omega, \\
y=h(X)=X_{1},
\end{gathered}
$$

where

$$
\begin{gathered}
f(X) \\
=\left[\begin{array}{c}
\frac{1}{m_{s}}\left[X_{2}^{3}\left(X_{3}-P_{a}\right) A_{e}-m_{s} g-\left(C_{3}^{(1)} X_{2}+C_{3}^{(2)} X_{2}^{2} C_{3}^{(3)} X_{2}^{3}\right)\right] \\
-\frac{\kappa \Delta V X_{2}}{V_{30}+\Delta V X_{1}} X_{3},
\end{array}\right], \\
g(X)=\left[\begin{array}{c}
0 \\
0 \\
\frac{\kappa R T_{3}}{V_{30}+\Delta V X_{1}}
\end{array}\right], \\
q(X)=\left[\begin{array}{c}
0 \\
-\frac{k_{s}}{m_{s}} \\
0
\end{array}\right],
\end{gathered}
$$

and the control input $u$ is the air mass flow rate $q_{m}$.

\section{Ride Height Adjusting System via Stochastic VSC Algorithm}

4.1. Disturbance Decoupling of Dynamic Ride Height Adjusting System. For Lie derivative $L_{q} h(X)=0$ and $L_{q} L_{f} h(X)=$ $\left(-k_{S} / m_{s}\right) \neq 0$, the interference characteristic index $v$ is 2 $[18,19]$. According to the differential geometry theory and $L_{g} L_{f} h(X)=L_{g} h(X)=0, L_{f} h(X)=X_{2}$, and $L_{f}^{2} h(X)=X_{3}$,

(2) can be decoupled as

$$
\begin{aligned}
\dot{X} & =\left[\begin{array}{c}
L_{f} h(X)+L_{g} h(X) u+L_{q} h(X) \omega \\
L_{f}^{2} h(X)+L_{g} L_{f} h(X) u+L_{q} L_{f} h(X) \omega \\
L_{f}^{3} h(X)+L_{g} L_{f}^{2} h(X) u+L_{q} L_{f}^{2} h(X) \omega
\end{array}\right] \\
& =\left[\begin{array}{c}
X_{2} \\
X_{3}+L_{q} L_{f} h(X) \omega \\
L_{f}^{3} h(X)+L_{g} L_{f}^{2} h(X) u+L_{q} L_{f}^{2} h(X) \omega
\end{array}\right],
\end{aligned}
$$

where $L_{q} L_{f}^{2} h(X)=C_{3}^{(1)}+2 C_{3}^{(2)} X_{2}+3 C_{3}^{(3)} X_{2}{ }^{2} k_{s} / m_{s}{ }^{2}$.

4.2. Variable Structure Control Approach to Design the Ride Height Adjusting System. The nonlinearity of the suspension system is composed of air spring and shock absorber, and the disturbance caused by road irregularity is the main characteristic of ride height adjusting system. VSC algorithm can obtain a perfect robustness to the interference and perturbation of the system [20] and will be proposed in 
this paper. The control input function $u(t)$ is solved by defining the switching function vector $s(t)$. Considering (4), the decoupled system is

$$
\dot{X}=\left[\begin{array}{c}
X_{2} \\
X_{3} \\
L_{f}^{3} h(X)
\end{array}\right]+\left[\begin{array}{c}
0 \\
0 \\
L_{g} L_{f}^{2} h(X)
\end{array}\right] u+\left[\begin{array}{c}
0 \\
L_{q} L_{f} h(X) \\
L_{q} L_{f}^{2} h(X)
\end{array}\right] \omega .
$$

The height adjusting system belongs to a single-input nonlinear system. Let $a(x)=L_{f}^{3} h(X), b(x)=L_{g} L_{f}^{2} h(X)$, $\Gamma(X)=\left[\begin{array}{c}0 \\ L_{q} L_{f} h(X) \\ L_{q} L_{f}^{2} h(X)\end{array}\right]$. Then, (5) is defined as $\dot{X}=f(X)+$ $g(X) u+q(X) \omega$. Because the mean value of the normal white noise $\omega$ is zero and is relative to the Wiener process [21], (5) is a typically Itô-type stochastic system [22]. It is obvious that the ride height system cannot be globally controlled in the bandwidth region with $100 \%$ of total probability. So, the stochastic VSC input $u(t)$ may ensure that the sliding mode of the system could be controlled by a certain probability $1-\delta<$ $100 \%$. We define that the switching function $s(t)$ must be controlled in a determined region by a certain probability, and it helps to solve the control law. The target equation can be represented as

$$
P\{|s(t)| \leq \mu\}=1-\delta
$$

If (6) is satisfied, the Itô-type stochastic system is asymptotically stable as a certain probability at the new balance point, and the control law of VSC input can be solved according to the above.

Firstly, define $e_{1}=X_{1}-X_{d}, e_{2}=\dot{X}_{1}-\dot{X}_{d}, e_{3}=\ddot{X}_{1}-\ddot{X}_{d}$, switching function $s(t)=c\left[\begin{array}{l}e_{1} \\ e_{2} \\ e_{3}\end{array}\right]$, and tracking height $X_{d}$, and substituting these into (5) yields

$$
\dot{e}=\left[\begin{array}{c}
X_{2} \\
X_{3} \\
a(x)
\end{array}\right]+\left[\begin{array}{c}
0 \\
0 \\
b(x)
\end{array}\right] u+\Gamma(X) \omega
$$

The part 1.2-Variable Structure Control Strategy in literature [23] can be extended to the nonlinear stochastic system. To get the control law of the ride height adjusting system, we define $m_{s}=E\{s(t) \mid X(t)\}$ and $\bar{v}=c \Gamma \omega$. Noting that the variance of $\omega$ is $\sigma^{2}$, we can see that $\bar{v}$ is a Gaussian procedure with zero mean and variance $(c \Gamma)^{2} \sigma^{2}$. At the same time, the variance can be appropriately identified according to the deflection of suspension. The control law can be solved according to three conditions of the switching function.

(1) Consider $s(t)>\theta^{-1} W$, where $\theta(0<\theta<1)$ is the regulating parameter of the switching function and $W$ is defined by the equation $\int_{-W}^{W}(1 / \sqrt{2 \pi} \bar{\sigma}) \exp \left(-x^{2} / 2 \bar{\sigma}^{2}\right) d x=$ $1-\varepsilon$. The equation $\int_{-\theta s(t)}^{\theta s(t)}(1 / \sqrt{2 \pi} \bar{\sigma}) \exp \left(-\left(x-m^{2}\right) / 2 \bar{\sigma}^{2}\right) d x=$ $1-\varepsilon$ has two solutions of $m_{1}^{+}(t)$ and $m_{2}^{+}(t)$ which satisfy $m_{1}^{+}(t)<m_{2}^{+}(t)$; then the control law is

$$
\begin{aligned}
u(t)=u^{+}(t) \in b^{-1}(x)[ & -a(x)-c_{1} e_{2}-c_{2} e_{3}+m_{1}^{+}(t)(t, x), \\
& \left.-a(x)-c_{1} e_{2}-c_{2} e_{3}+m_{2}^{+}(t)(t, x)\right] .
\end{aligned}
$$

(2) Consider $s(t)<-\theta^{-1} W$. The equation $\int_{\theta s(t)}^{-\theta s(t)}(1 / \sqrt{2 \pi} \bar{\sigma}) \times$ $\exp \left(-(x-m)^{2} / 2 \bar{\sigma}^{2}\right) d x=1-\varepsilon$ has only two solutions of $m_{1}^{-}(t)$ and $m_{2}^{-}(t)$ which satisfy $m_{1}^{-}(t)<m_{2}^{-}(t)$; then the control law is

$$
\begin{aligned}
u(t)=u^{-}(t) \in b^{-1}(x)[ & -a(x)-c_{1} e_{2}-c_{2} e_{3}+m_{1}^{-}(t)(t, x), \\
& \left.-a(x)-c_{1} e_{2}-c_{2} e_{3}+m_{2}^{-}(t)(t, x)\right] .
\end{aligned}
$$

(3) Consider $|s(t)|<\theta^{-1} W$ :

$$
u(t)=u_{e q}(t)=b^{-1}(x)\left[-a(x)-c_{1} e_{2}-c_{2} e_{3}\right] .
$$

The ideal design objective is that the confidence interval $1-\varepsilon$ is as large as possible, and the bandwidth $\theta^{-1} W_{c}$ of sliding motion is as small as possible, but these conditions are contradictory. The parameter of $\varepsilon$ and the sliding motion band can be determined in the practical application.

4.3. Simulation of Dynamic Ride Height Control System. Control strategies such as stochastic VSC and PID control were compared by means of computational simulations with the help of the software MATLAB/Simulink. Simulation results were conducted to validate the accuracy and effectiveness of the proposed control algorithm. The simulation model consists of the variable mass thermodynamics system model of air spring, the quarter vehicle model, and the controller, as shown in Figure 3. The program of control algorithm is realized by using $\mathrm{S}$-function, and this may be coded to make dSPACE controller acquaint (see Section 5). Since the disturbance magnitude is determined by the irregularity of road surface and the vehicle speed, the road model is built by the integral white-noise as shown in Figure 4, and the disturbance data may be the equipment of road simulator by format changing. Taking B level typical road and the speed $50 \mathrm{~km} / \mathrm{h}$ as example, the disturbance magnitude is calculated after a low-pass filter of the tire and suspension damping, as shown in Figure 5.

For the comparison of stochastic VSC and PID control algorithm, the same adjusting time needs to be ensured, and the control parameters of $K_{P}$ for PID $[24,25]$ and $c_{1}$ for VSC are predetermined according to the height adjusting time. Table 1 shows the major parameters of the ride height adjusting system used in the simulation. The ride height adjustment of ECAS has three switchmodes of "High Mode," "Normal Mode", and "Low Mode" in this study. "Normal Mode" is the normal ride height, and other modes are applied in special conditions. The height changing distance between "Normal Mode" and "High Mode" is $20 \mathrm{~mm}$, and the height changing distance between "Normal Mode" and "Low Mode" 


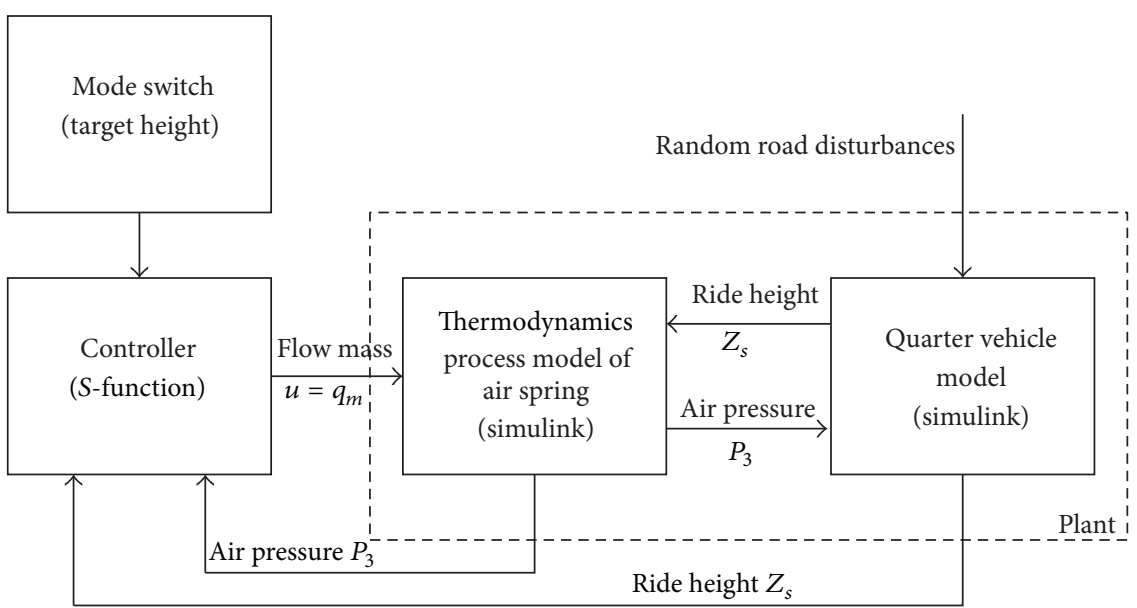

Figure 3: Simulation scheme.

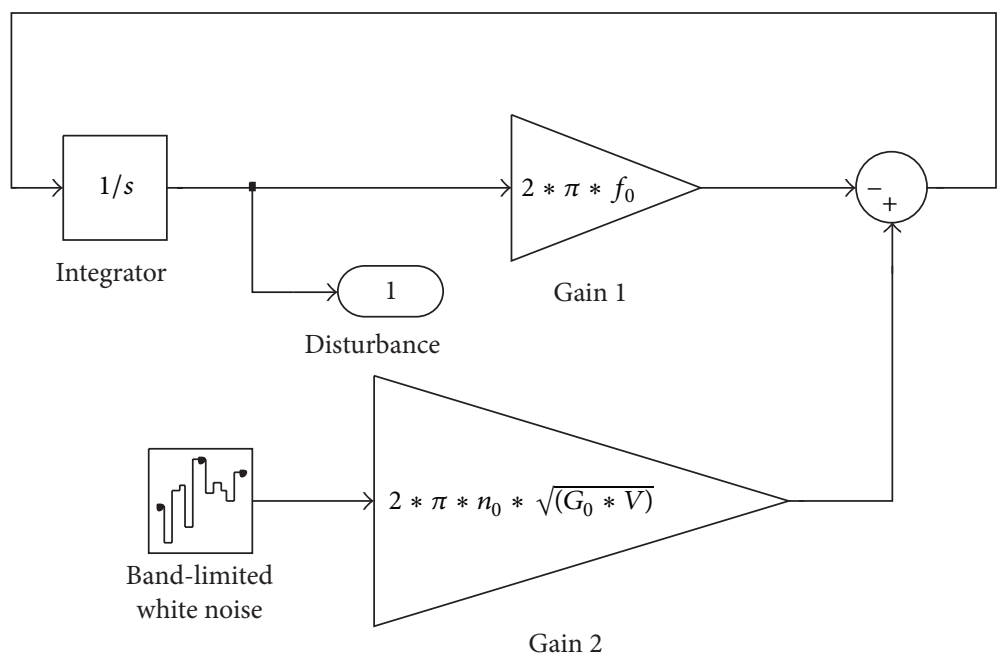

FIGURE 4: Road simulink model based on the integral white-noise.

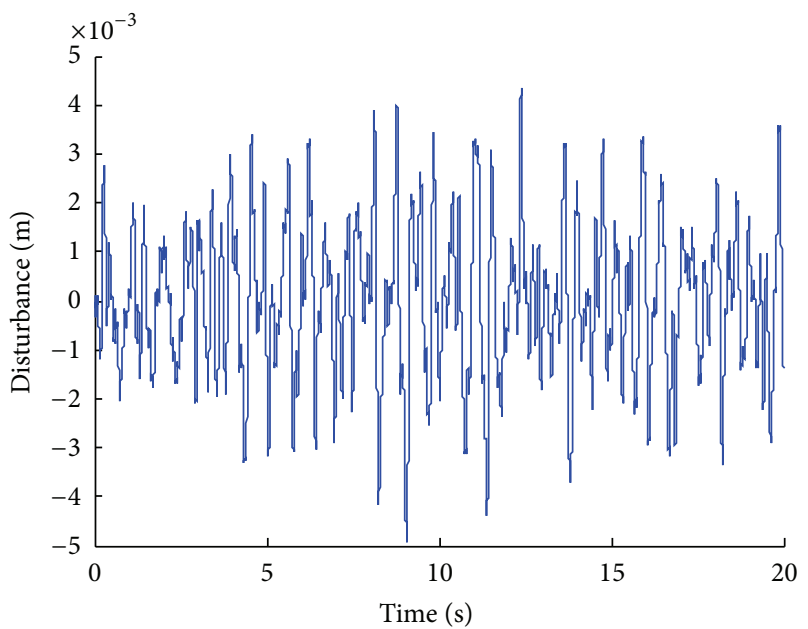

FIGURE 5: Disturbance magnitude of the B level typical road and the speed $50 \mathrm{~km} / \mathrm{h}$.
TABLE 1: Values of the ride height adjusting system parameters.

\begin{tabular}{lc}
\hline Parameters & Value \\
\hline Sprung mass $M(\mathrm{~kg})$ & 1074 \\
$\begin{array}{l}\text { First degree term of damping coefficient } C_{3}^{(1)} \\
(\mathrm{N} \cdot \mathrm{s} / \mathrm{m})\end{array}$ & 8832 \\
$\begin{array}{l}\text { Quadratic term of damping coefficient } C_{3}^{(2)} \\
\left((\mathrm{N} \cdot \mathrm{s} / \mathrm{m})^{2}\right)\end{array}$ & 6245 \\
$\begin{array}{l}\text { Third degree term of damping coefficient } \\
C_{3}^{(3)}\left((\mathrm{N} \cdot \mathrm{s} / \mathrm{m})^{3}\right)\end{array}$ & -1568 \\
Effective area $A_{e}\left(\mathrm{~m}^{2}\right)$ & 0.019 \\
Volume changing rate $\Delta V\left(\mathrm{~m}^{3} / \mathrm{m}\right)$ & 0.025 \\
Initial effective volume $V_{30}\left(\mathrm{~m}^{3}\right)$ & 0.0048 \\
Volume of air reservoir $V_{1}\left(\mathrm{~m}^{3}\right)$ & 0.06 \\
Pressure of air reservoir $P_{1}(\mathrm{MPa})$ & 1.0
\end{tabular}




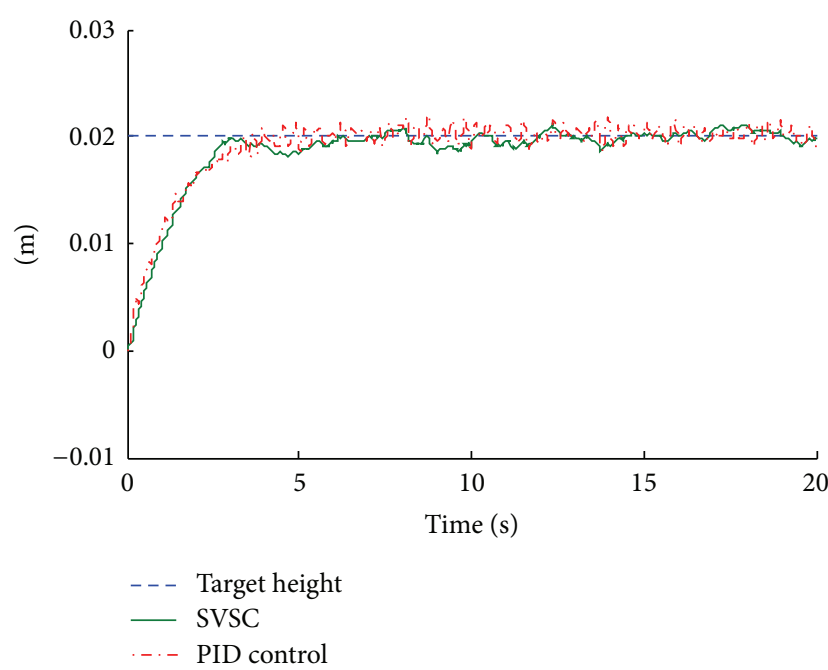

FIGURE 6: Lifting of the ride height.

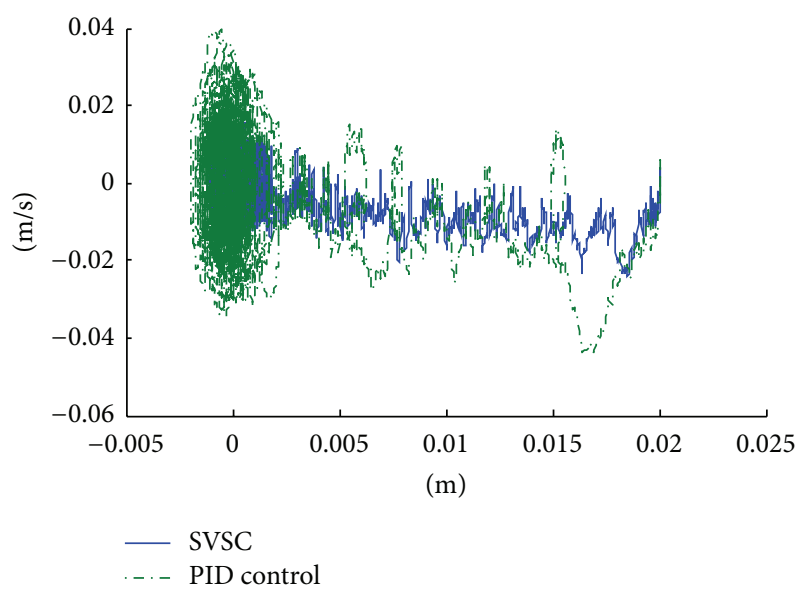

FIGURE 7: Lifting trajectory of height errors.

is $30 \mathrm{~mm}$. So, we choose the control parameters $K_{P}=0.8$, $K_{I}=0.2$, and $K_{D}=0.5$ for PID control and $c_{1}=15$ and $c_{2}=10$ for VSC.

The experimental results are obtained by applying the stochastic VSC and PID control techniques. Figures 6 and 7 show the results of the ride height lifting condition for the simulations. With the same adjusting time $4 \mathrm{~s}$ of both control methods, we can see from Figure 6 that the standard deviation using VSC technique is $3.4 \mathrm{~mm}$, and the one using PID control technique is $3.6 \mathrm{~mm}$. Figures 8 and 9 show the results of the ride height lowing condition for the simulations. By using the same analyzing method, it is observed from Figure 8 that the standard deviation using VSC technique is $4.8 \mathrm{~mm}$ and the one using PID control technique is $5.2 \mathrm{~mm}$, under the same adjusting time $5 \mathrm{~s}$ of both control methods. Moreover, it is known from the trajectory of height errors in Figures 7 and 9 that the adjusting process of VSC system is more stable. Therefore, the simulation results show that the controller can greatly improve the adjusting stability and

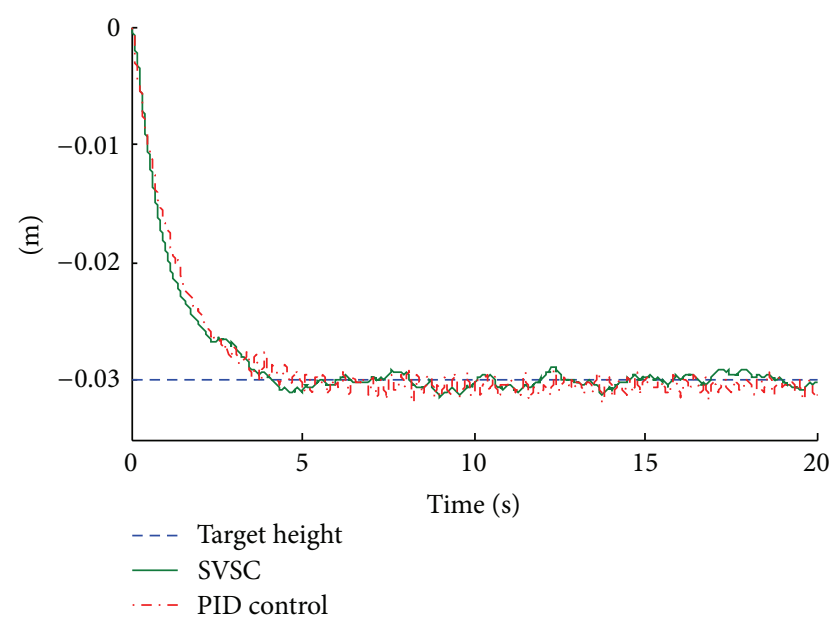

FIGURE 8: Lowering of the ride height.

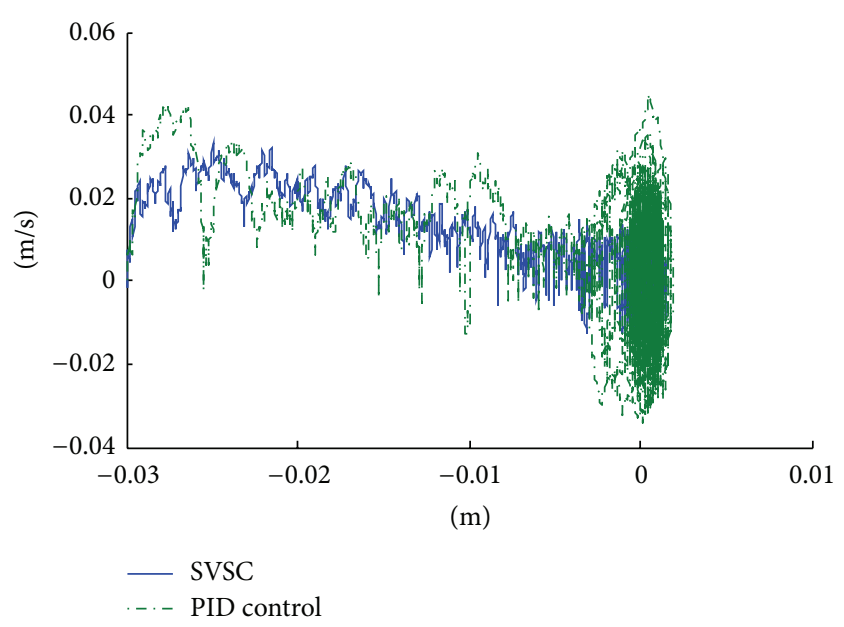

Figure 9: Lowing trajectory of height errors.

the system oscillation by using the stochastic VSC technique. Some performance comparison is shown in Table 2.

\section{Test and Validation}

The actual adjusting test was conducted with a semiphysical rig equipped with a ride height control system, where the full character was equivalent to six coil springs. Payload of the ride height system can be changed by increasing or decreasing the amount of the iron-sand bags. Random road disturbances created by the simulink model were input into the system of the Digital Hydraulic Servo Test Machine of INSTRON 8800. Meanwhile, the proposed stochastic VSC algorithm was programmed by means of Matlab/Simulink and directly downloaded into the dSPACE/RapidPro platform. In addition, a compressor was used to supply the high pressure air for the ride height system. In current testing applications, the control input calculated by stochastic SVC technique is the mass flow rate $u$, but the ON-OFF solenoid valve has just two states which cannot continuously adjust the mass flow rate. 
TABLE 2: Performance index comparison of VSC and PID technique.

\begin{tabular}{|c|c|c|c|c|}
\hline \multirow{2}{*}{ Performance index } & \multicolumn{2}{|c|}{ SVSC } & \multicolumn{2}{|c|}{ PID } \\
\hline & Lifting & Lowering & Lifting & Lowering \\
\hline Height deviation (mm) & 3.4 & 4.8 & 3.6 & 5.2 \\
\hline Acceleration amplitude of vehicle body $\left(\mathrm{m} / \mathrm{s}^{2}\right)$ & 5.61 & 5.63 & 5.96 & 6.24 \\
\hline Acceleration of vehicle body r.m.s $\left(\mathrm{m} / \mathrm{s}^{2}\right)$ & 1.08 & 1.09 & 1.14 & 1.17 \\
\hline Height adjusting time $(\mathrm{s})$ & 4 & 5 & 4 & 5 \\
\hline
\end{tabular}

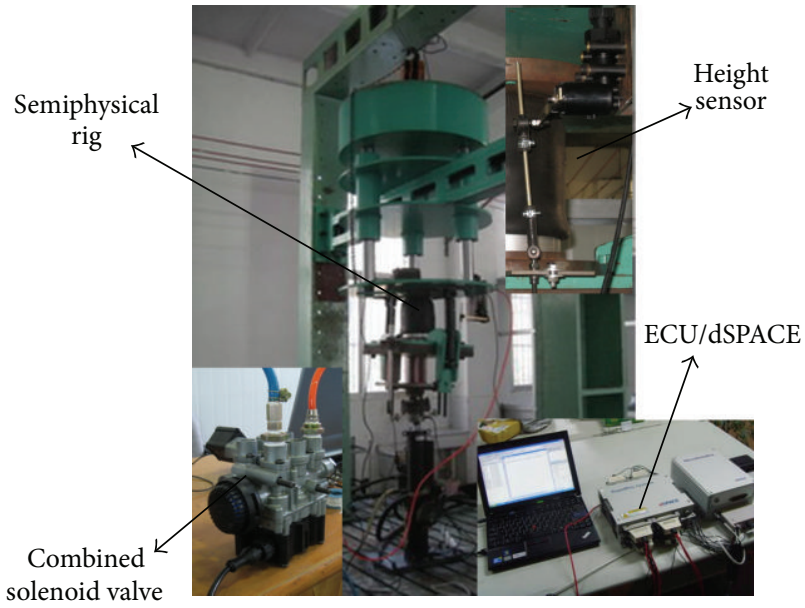

FIGURE 10: Testing rig of the ride height adjustment system.

So, the average mass flow rate during 0.062 seconds of the pulse period is controlled by the PWM duty cycle. Since the response speed of solenoid valve is limited, a working deadzone of solenoid valve should be no less than 0.025 seconds. In addition, the solenoid valve for charging and discharging the compressed gas does not allow opening simultaneously which can reduce energy consumption. Figure 10 shows the configuration of the semi-physical rig test platform. The pressure of air spring is measured by an installed pressure sensor, and the ride height changing is measured by an installed height sensor.

Figures 11, 12, 13, and 14 show the testing results for the proposed control system. The adjusting time of both height lifting and lowering is over $5 \mathrm{~s}$, because the route loss of the pipeline, the pressure decreasing of the air reservoir, and the saturation of control input jointly contribute to the more adjusting time than that of simulations. Nevertheless, the whole height adjusting process has no significant overshoot, and the proposed control system can stably switch the height mode and weaken the effect of disturbances. This result shows the robustness of the proposed controller.

\section{Conclusions}

This paper focuses on the ride height control system under the random road disturbances. The nonlinear model of ride height system, which contains the aerothermodynamics and vehicle dynamic processes, is established. On the basis of the

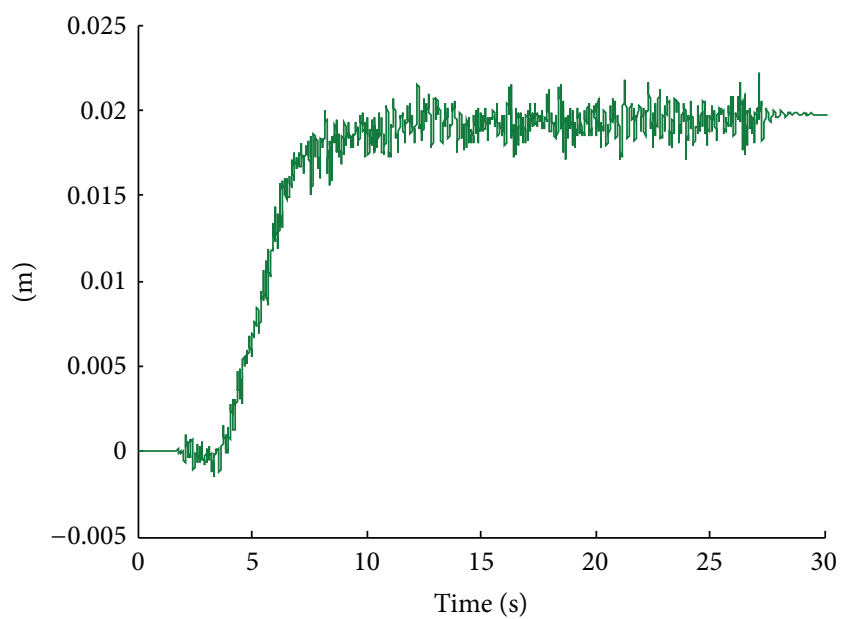

FIGURE 11: Height lifting testing.

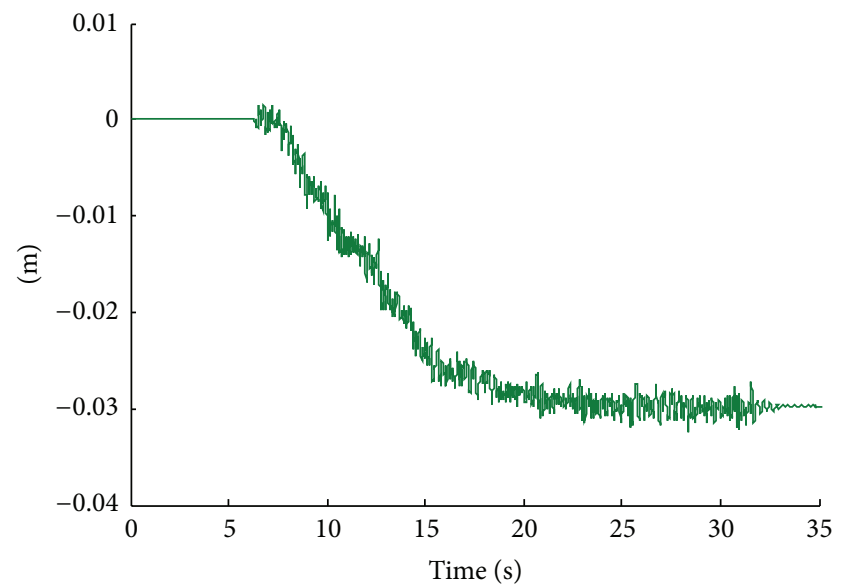

FIGURE 12: Height lowering testing.

present simulations and test, the following conclusion can be made.

(i) The ride height adjusting system is modeled as an Itô-type stochastic nonlinear system. Zero stability of the ride adjusting system will not be obtained by the control algorithm. The control law is obtained by using Gauss normal distribution in a certain probability, which can be carried out to weaken the random disturbance of the road irregularities. 


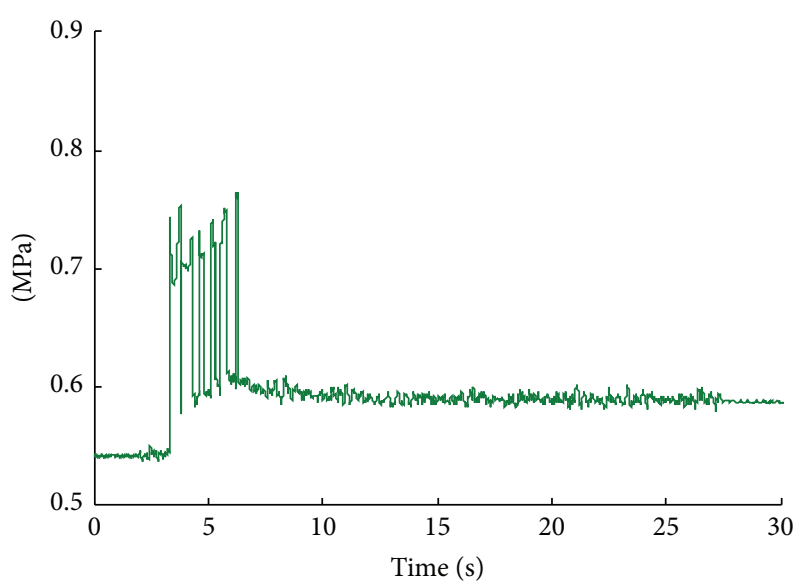

FIGURE 13: Pressure changing of air spring of ride height lifting with random disturbances.

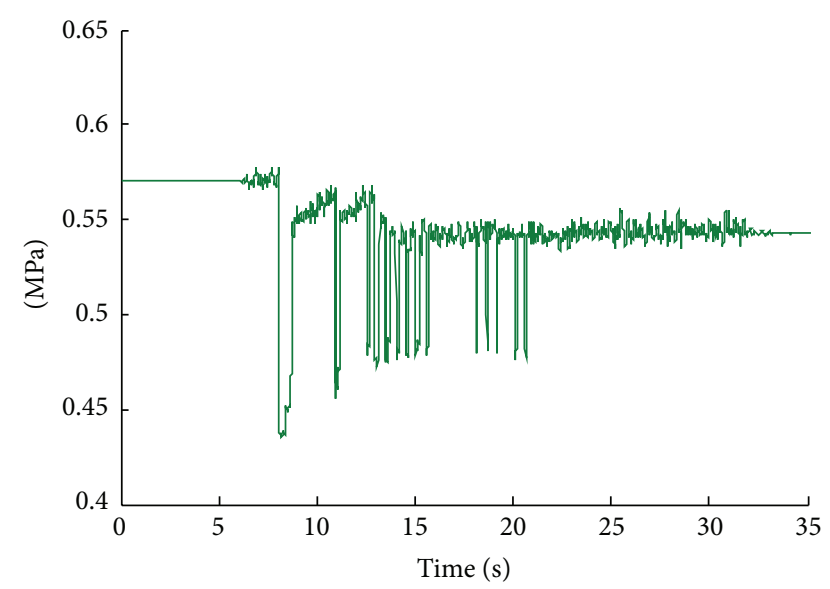

FIGURE 14: Pressure changing of air spring of ride height lowering with random disturbances.

(ii) Under the same adjusting time, the proposed controller and PID controller both can achieve the same height accuracy, but the proposed controller has a better ride performance than that of the PID controller during the height adjusting process, which shows that the proposed controller is suitable for the current system.

(iii) Rig tests show that the proposed control method is feasible and can satisfy the stability performance of the ride height adjusting system.

\section{Conflict of Interests}

No conflict of interests exists in the submission of this paper, and the paper is approved by all authors for publication.

\section{Disclosure}

The authors would like to declare that the work described was an original research that has not been published previously and is not under consideration for publication elsewhere, in whole or in part.

\section{Acknowledgments}

This study was supported by the National Natural Science Foundation of China under Grant no. 51105177, the Research Fund for the Doctoral Program of the Higher Education of China under Grant no. 20113227120015, the Natural Science Foundation of Jiangsu Province under Grant no. BK20131255, the Scientific Research Foundation for Advanced Talents, Jiangsu University under Grant no. 11JDG047, and the Hunan Provincial Natural Science Foundation of China under Grant 12JJ6036. Xing Xu gratefully acknowledges these support agencies. The authors also wish to extend their sincere acknowledgments to the anonymous reviewers for providing many invaluable references and suggestions.

\section{References}

[1] J. Youn, I. Park, and M. Sunwoo, "Heuristic resource allocation and scheduling method for distributed automotive control systems," International Journal of Automotive TechNology, vol. 14, no. 4, pp. 611-624, 2013.

[2] M. Hirose, S. Matsushige, S. Buma, and K. Kamiya, “TOYOTA electronic modulated air suspension system for the 1986 soarer," IEEE Transactions on Industrial Electronics and Control Instrumentation, vol. 35, no. 2, pp. 193-200, 1988.

[3] A. W. Burton, A. J. Truscott, and P. E. Wellstead, "Analysis, modelling and control of an advanced automotive self-levelling suspension system," IEE Proceedings: Control Theory and Applications, vol. 142, no. 2, pp. 129-139, 1995.

[4] A. Bemporad and M. Morari, "Verification of hybrid systems via mathematical programming," in Hybrid Systems: Computation and Control, No, vol. 1569, pp. 31-45, 1999.

[5] Z. B. Shuai, H. Zhang, J. M. Wang, J. Q. Li, and M. G. Ouyang, "Combined AFS and DYC control of four-wheel-independentdrive electric vehicles over CAN network with time-varying delays," IEEE Transactions on Vehicular Technology, 2013.

[6] Y. Song, "Study on ride height PID control technology of air suspension vehicle," Journal of Hubei Automotive Industries Institute, vol. 21, no. 2, pp. 1-4, 2007.

[7] Z. Chen, D. Jin, G. Ma, X. Huang, and L. Zhao, "Simulation of variable structure control strategy in combination with PID for vehicle body height," Journal of Tsinghua University, vol. 39, no. 8, pp. 72-75, 1999.

[8] W. B. Yu, L. Z. Zhang, and N. Li, "Study of the fuzzy control of air suspension of vehicle height system," Electronic Instrumentation Customer, vol. 13, no. 2, pp. 6-8, 2006.

[9] Q. Y. Yang, Research on Matching and Inflation/Deflating of Suspension System in ECAS-Bus, Jiangsu University, Zhenjiang, China, 2008.

[10] X. Xu, Z. Chen, L. Quan, Z. Li, and K. Zhou, "Real-time tracking of ride height for bus with electronically controlled air suspension," Journal of Mechanical Engineering, vol. 47, no. 2, pp. 136-141, 2011.

[11] X. Xu, Z. Z. Chen, and Z. X. Li, "Investigation on modeling and control of body height adjustment for bus with electrically controlled air suspension," Automobile Technology, no. 11, pp. 42-46, 2009. 
[12] Y. Y. Feng and Q. G. Du, "Investigation on body height adjustment for semi-trailer with electrically controlled air suspension and design of fuzzy/PWM controller," Science Technology and Engineering, vol. 32, no. 10, pp. 7974-7979, 2010.

[13] H. Kim and H. Lee, "Height and leveling control of automotive air suspension system using sliding mode approach," IEEE Transactions on Vehicular Technology, vol. 60, no. 5, pp. 20272041, 2011.

[14] H. Zhang, Y. Shi, and M. X. Liu, " $H_{\infty}$ step tracking control for networked discrete-time nonlinear systems with integral and predictive actions," IEEE Transactions on Industrial Informatics, vol. 9, no. 1, pp. 337-345, 2013.

[15] H. Zhang and Y. Shi, "Observer-based $H_{\infty}$ feedback control for arbitrarily time-varying discrete-time systems with intermittent measurements and input constraints," Journal of Dynamic Systems, Measurement, and Control, vol. 134, no. 6, Article ID 061008, 12 pages, 2012.

[16] H. Zhang, Y. Shi, and A. Saadat Mehr, "Robust non-fragile dynamic vibration absorbers with uncertain factors," Journal of Sound and Vibration, vol. 330, no. 4, pp. 559-566, 2011.

[17] X. Xu, Study on Control of Ride Height Nonlinear System for Bus with ECAS, Jiangsu University, Zhenjiang, China, 2010.

[18] M. Riccardo and T. Patrizio, Design of Nonlinear SystemAdaptive and Robust Control of Differential Geometry, Publishing House of Electronics Industry, Beijing, China, 2006.

[19] H. Zhang, Y. Shi, and A. S. Mehr, "Robust $H_{\infty}$ PID control for multivariable networked control systems with disturbance/noise attenuation," International Journal of Robust and Nonlinear Control, vol. 22, no. 2, pp. 183-204, 2012.

[20] P. Wilfrid and P. B. Jean, Sliding Mode Control in Engineer, Marcel Dekker, New York, NY, USA, 2002.

[21] B. T. Wu, Q. S. Li, and Y. W. Yang, Stochastic Processes and Stochastic Differential Equations, University of Electronic Science and Technology of China Press, Chengdu, China, 1994.

[22] H. Zhang, Y. Shi, and B. X. Mu, "Optimal $H_{\infty}$-based linearquadratic regulator tracking control for discrete-time TakagiSugeno fuzzy systems with preview actions," Journal of Dynamic Systems, Measurement, and Control, vol. 135, no. 4, Article ID 044501, 5 pages, 2013.

[23] F. Zheng, M. A. Cheng, and W. B. Gao, "Incomplete state information variable structure control of stochastic systems," Acta Aeronautica et Astronautica Sinica, vol. 15, no. 7, pp. 870876, 1994.

[24] K. J. Åström and T. Hägglund, "Revisiting the Ziegler-Nichols step response method for PID control," Journal of Process Control, vol. 14, no. 6, pp. 635-650, 2004.

[25] H. Zhang, Y. Shi, and A. Saadat Mehr, "Robust static output feedback control and remote PID design for networked motor systems," IEEE Transactions on Industrial Electronics, vol. 58, no. 12, pp. 5396-5405, 2011. 


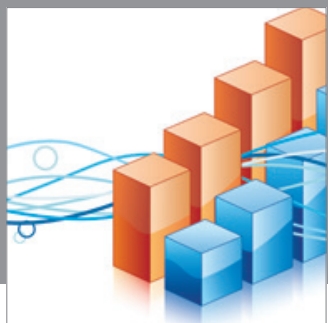

Advances in

Operations Research

mansans

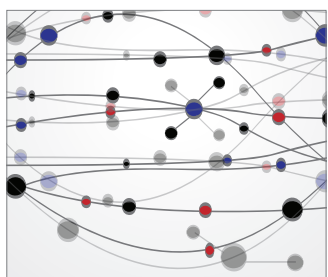

The Scientific World Journal
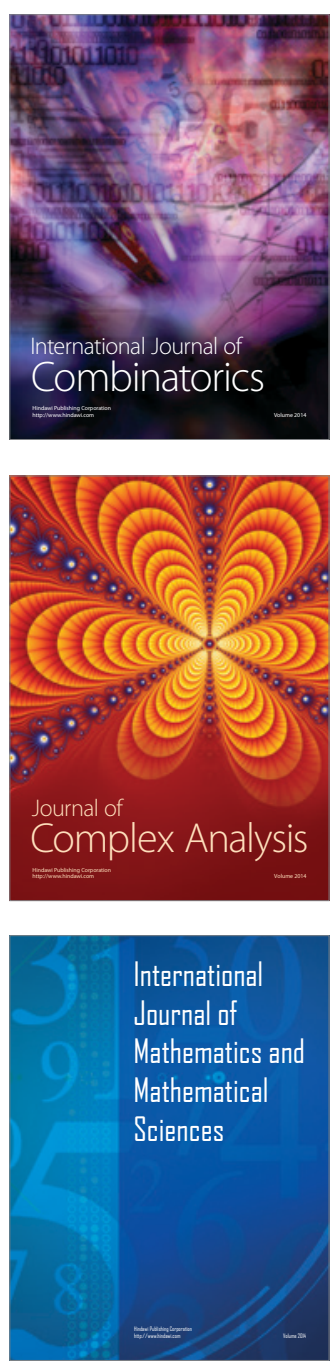
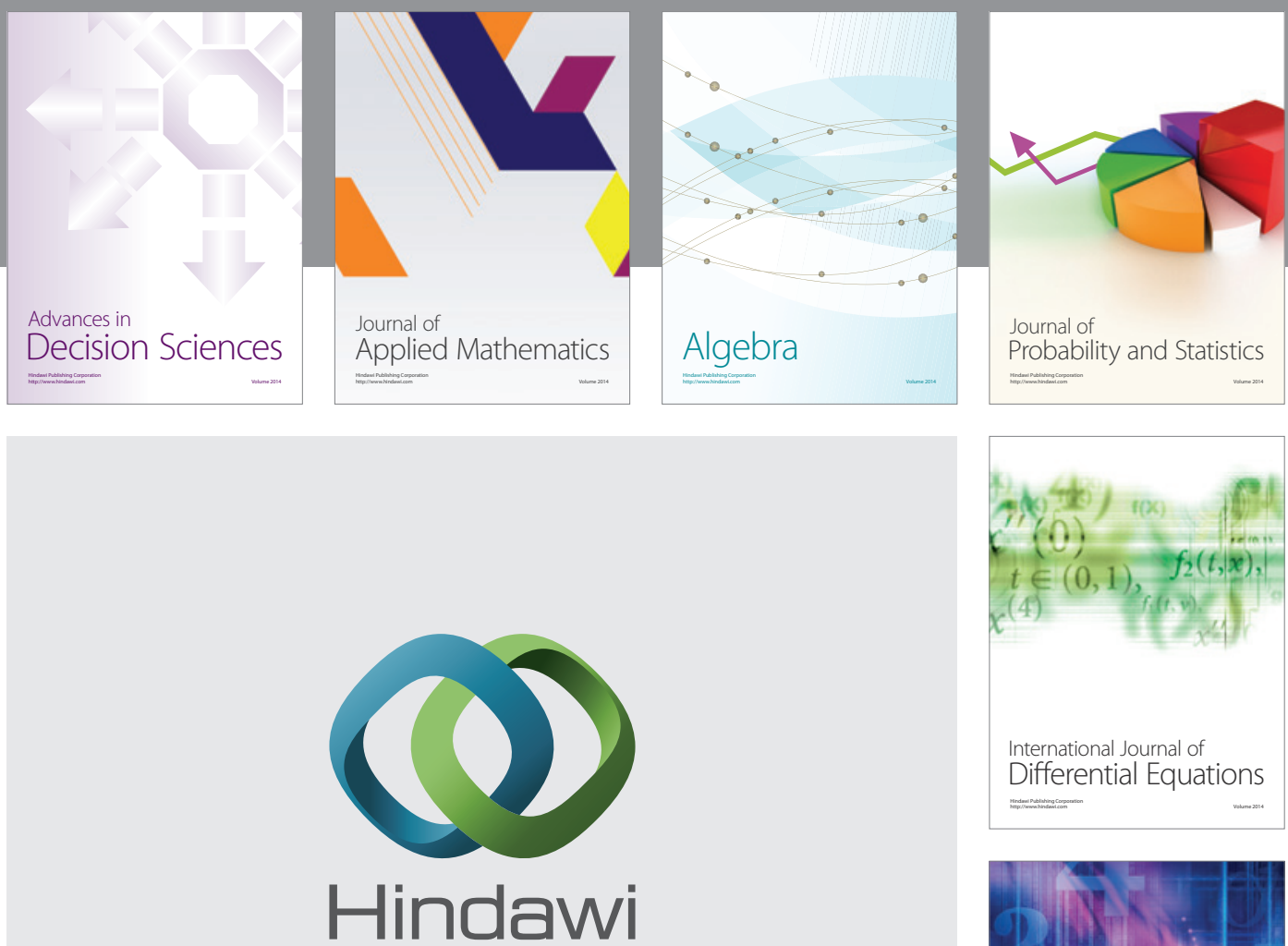

Submit your manuscripts at http://www.hindawi.com
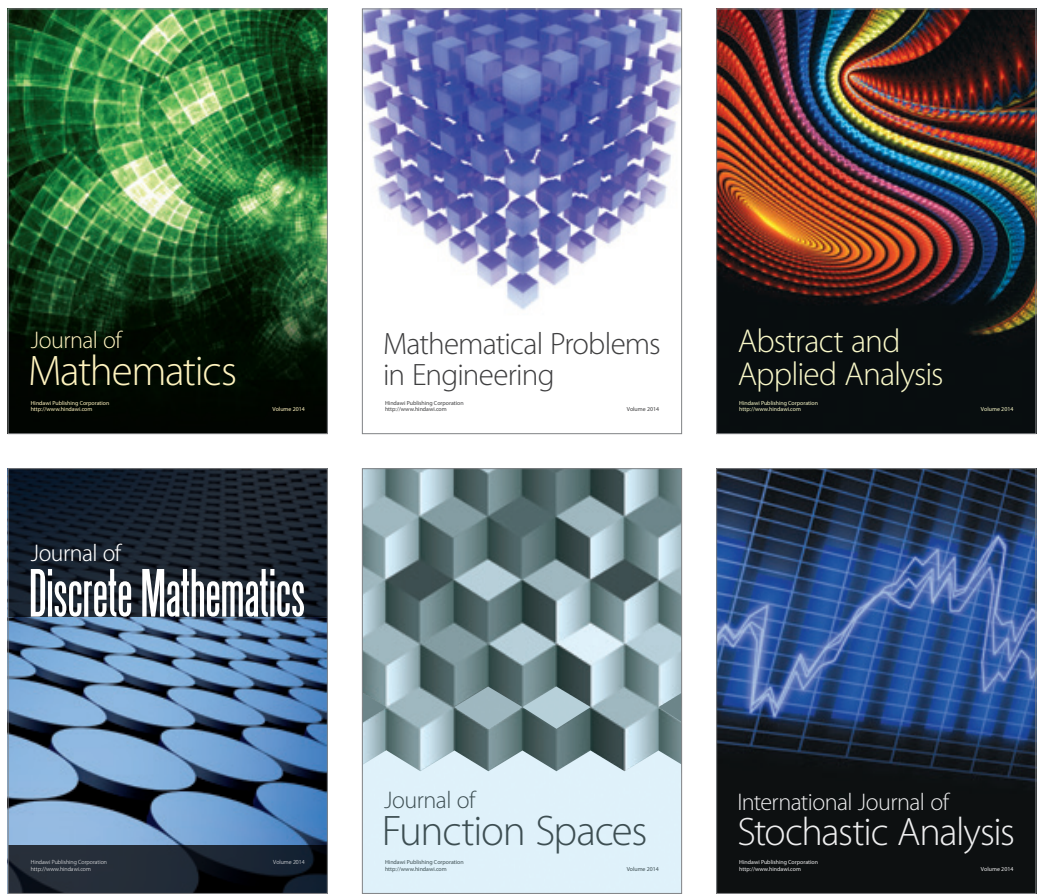

Journal of

Function Spaces

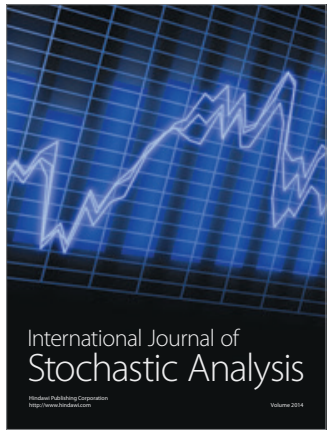

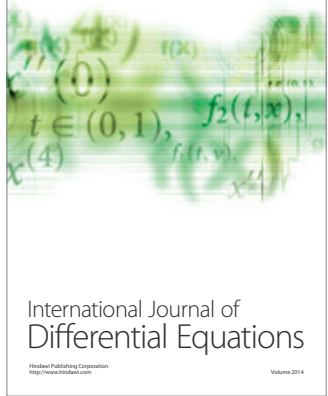
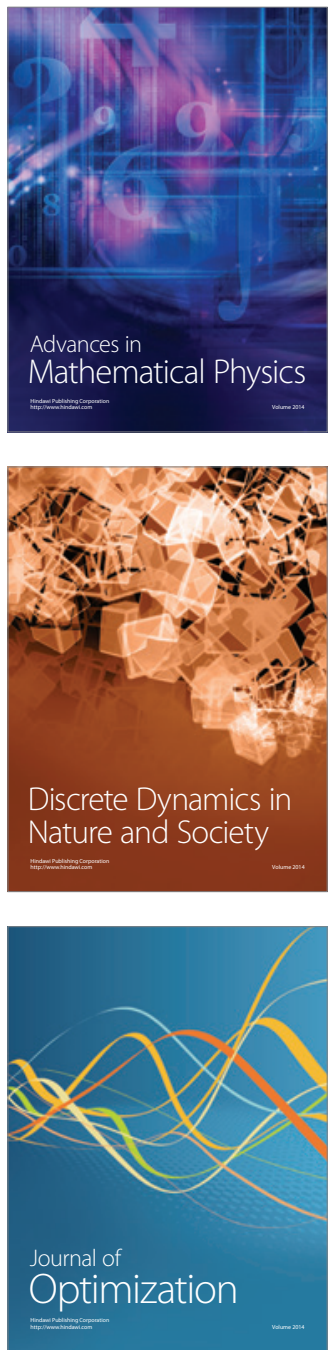